\title{
Research On The Risk And Benefit Cooperative Decision of Reservoir Flood Limited Water Level
}

\section{Xiaoying Li}

Hohai University

Yan Zhang ( $\boldsymbol{\nabla}$ 744631343@qq.com )

Hohai University https://orcid.org/0000-0001-6397-2200

\section{Zechun Tong}

Hohai University

Guo-Yue Niu

The University of Arizona

\section{Research Article}

Keywords: flood season segmentation, extreme risk rate, multi-objective cooperative decision, Nash negotiation, adjustment of flood limited water level

Posted Date: January 31st, 2022

DOI: https://doi.org/10.21203/rs.3.rs-1245741/v1

License: (c) (i) This work is licensed under a Creative Commons Attribution 4.0 International License. Read Full License 
1 Date written: $10^{\text {th }}$ January 2022

\section{Research On The Risk And Benefit Cooperative Decision Of}

25 Number of words: 6366 (main text)

26 Number of tables: 12

27 Number of figures: 3

\section{*Corresponding author}

Yan Zhang, Master degree candidate. 210098, China.

E-mail address: 191302030016@hhu.edu.cn

\section{Acknowledgements} of China (2018YFC0407902).

\section{Reservoir Flood Limited Water Level}

Xiaoying Li ${ }^{\mathrm{a}}$, Yan Zhang ${ }^{\text {a,* }}$, Zechun Tong ${ }^{\mathrm{a}}$, Guo-Yue Niu ${ }^{\mathrm{b}}$

${ }^{a}$ College of Water Conservancy and Hydropower Engineering, Hohai University, Nanjing, China.

${ }^{\mathrm{b}}$ Department of hydrology and atmospheric sciences, the University of Arizona, Tucson, Arizona, USA

College of Water Conservancy and Hydropower Engineering, Hohai University, Nanjing,

ORCID number: https://orcid.org/0000-0001-6397-2200

This study is financially supported by The National Key Research and Development Program 
Abstract: The inconsistency between water consumption and the annual rainfall distribution makes it important to make full use of the flood water resource. The adjustment of the flood limited water level (FLWL) is an effective way to improve the flood water utilization, where the staged control of the FLWL plays an important role. Flood season segmentation is the basis for determining the FLWL and tapping the utilization potential of flood resources. The circular distribution method is used to segment, and the relative frequency method is used to verify. Maintaining the balance between benefit and flood control safety is the key work for the FLWL decision. The performances of water supply and hydropower generation are selected to be benefit index, and the extreme risk rate is risk index. Based on the game theory, the multi-objective cooperative decision-making model is established. Nash negotiation solution of staged FLWL is obtained by Nash negotiation theorem. The optimal scheme is determined according to the fuzzy pattern recognition theory. A reservoir is taken as an example, firstly, considering that the risk and benefit are equally valued, the FLWL of the optimal scheme in the pre-flood season is $129.0 \mathrm{~m}$, and the post-flood season is $128.5 \mathrm{~m}$. By adjusting the preference value for risk and benefit, the optimal FLWL scheme under different preferences for risk and benefit in each stage is determined.

Keywords: flood season segmentation; extreme risk rate; multi-objective cooperative decision; Nash negotiation; adjustment of flood limited water level 


\section{Introduction}

Reservoir is significant for comprehensive development and management of water resources. It plays an important role in meeting social water demand (Chen et al., 2013; Jiang et al., 2015; Zhou et al., 2014). Reservoir operation is an effective measure to realize the optimal allocation of water resources. Rainfall in China is unevenly distributed throughout the year, and most of the annual runoff is concentrated in the flood season. The control of flood limited water level (FLWL) is a significantly resultful method of reservoir operation. (Li et al., 2010; Liu et al., 2015). Flood season segmentation is a fundamental prerequisite for adjusting the FLWL and tapping the utilization potential of flood resources. It is an important subject to alleviate the contradiction between flood control and utilization benefit.

The study of flood season segmentation (Chen et al., 2015; Jiang et al., 2019) has gone through a process of in-depth research from qualitative to quantitative, from single index to multiple indexes. Advances primarily involve the techniques of mathematical statistics method, genesis analysis method, fuzzy clustering method, fractal theory, relative frequency and directional statistics method, and so on. The mathematical statistics and genesis analysis methods (Black A and Werritty, 1997; Singh et al., 2005) needed a large number of flow data and hydrometeorological analysis. They had high requirements for data and can be time-consuming. Besides, the results involved subjectivity in deciding the segmentation. The fuzzy clustering method (Ju et al., 2020) made use of soft decisions through the use of membership functions, It determined the staging results according to the selected threshold value, which is subjective. The results of fractal theory (Qian et al., 2018) were relatively objective, but the workload of analysis and calculation was heavy. The directional statistics method (Cunderlik et al., 2004a; Cunderlik et al., 2004b) convert the 
occurrence time of each sample into radians and draw the vector statistical graph to determine the segmentation. It only considered the occurrence time of flood, and its results are mainly judged visually according to the distribution density of data points in the vector graph, which is subjective. The circular distribution method (Fang, et al., 2007) had the characteristics of simple and convenient calculation and flexible analysis. It comprehensively considered the concentration degree and concentration period of flood occurrence. It also takes the flood magnitude into account. To a certain extent, the circular distribution method reduced the influence of subjectivity. Based on the analysis of the daily discharge data in 62 years, the circular distribution method will be implemented to segment the flood season in this study, and the relative frequency method will be used to verify.

For the control of FLWL of a single reservoir, on the premise of meeting the downstream flood control safety, the utilization of flood resources will be improved by the adjustment of the FLWL (Huang et al., 2017). The benefits of hydropower generation and water supply can be added. However, adjusting the FLWL will not only improve the utilization efficiency, but also increase the flood control risk (Zhou et al., 2015). There have been many studies on how to realize the effective control of the FLWL. The staged control of FLWL is proved to be a more helpful measure. The widely used methods (Jiang et al., 2015a) mainly include fuzzy set analysis method (Yun et al., 2008) and multi-objective optimization method (Chen et al., 2020; Ma et al., 2020; Xie et al., 2018; Ouyang et al., 2015), etc. Zhou et al. (2009) taking Biliuhe reservoir as an example, for the purpose of determining the FLWL in the post-flood season, they divided the general objectives of FLWL control into flood control and benefit. They established an index set, considered each index layer by layer, and analyzed it by using multi-layer and multi-objective fuzzy optimization theory. Finally, 
the optimal membership degree of each FLWL scheme was obtained. Liu et al. (2019) considered the comprehensive needs of flood control and hydropower generation. Based on dynamic control method, a multi-objective optimal operation model for dynamic control of FLWL of cascade reservoirs was constructed. Researchers have made extraordinary achievements in producing suitable operating methods, whereas most of the existing studies do not consider the FLWL of each stage in the flood season separately. Generally speaking, in order to ensure the flood control safety in the pre-flood season, the decision-makers often prefer risk, while in the post-flood season, in order to ensure the benefit, the decision-makers often prefer benefit. Therefore, the FLWL in different stages should be considered severally. The preference is adjusted to coordinate the relationship between benefit and risk.

After staging the flood season, this paper has established the benefit index set and risk index set of FLWL control based on game theory. A multi-objective cooperative decision-making model of risk and benefit is set up. Taking a reservoir as an example, according to the flood control task and design flood hydrograph, the FLWL in the main flood season was chosen as the original design. The adjustment mainly focused on the pre-flood season and post-flood season. The extreme risk rate was selected as the risk index. In addition to the increased water supply benefit, the increased hydropower generation benefit was also selected as the benefit index. Using Nash negotiation theory, the nonlinear programming method was used to solve the model. On the basis of fuzzy pattern recognition theory, the membership degree of each scheme was calculated to determine the optimal scheme. Finally, considering the different preferences for risk and benefit in different sub-seasons, taking the current point as the base point of negotiation. The optimal scheme under different preferences was obtained by adjusting the current point. 


\section{The division of flood season}

\subsection{Circular distribution method}

\subsubsection{Concept}

Circular distribution method is a statistical method. It transforms the periodic data into linear through trigonometric function transformation. The circular distribution method regards the flood events as a vector, and then calculates the vector eigenvalues to determine the flood season segmentation (Chen et al., 2010).

\subsubsection{Computing method}

Suppose that the length of the calculation period is $T$. Meanwhile, the occurrence time of the flood peak of the $i$-th flood sample is $D_{i}$, and the magnitude is $q_{i}$. The equations of the coordinate value $\left(x_{i}, y_{i}\right)$ of flood occurrence time without considering and considering the flood magnitude are as follows:

$$
\begin{gathered}
\left(x_{i}, y_{i}\right)=\left\{\begin{array}{l}
\left(\cos \alpha_{i}, \sin \alpha_{i}\right) \quad \text { without considering the magnitude of flood } \\
\left(q_{i} \cos \alpha_{i}, q_{i} \sin \alpha_{i}\right) \text { considering the magnitude of flood }
\end{array}\right. \\
(\bar{x}, \bar{y})=\left(\sum_{i=1}^{N} x_{i} / N, \sum_{i=1}^{N} y_{i} / N\right)
\end{gathered}
$$

Where $N$ is the sample size, and $\alpha_{i}=D_{i} \frac{2 \pi}{T}$ is the occurrence time of the $i$-th flood.

The concentration period $\bar{\alpha}$ and concentration $r$ are respectively:

$$
\bar{\alpha}= \begin{cases}\arctan \bar{y} / \bar{x} & \bar{x}>0, \bar{y}>0 \\ 2 \pi+\arctan \bar{y} / \bar{x} & \bar{x}>0, \bar{y}<0 \\ \pi+\arctan \bar{y} / \bar{x} & \bar{x}<0 \\ \pi / 2 & \bar{x}=0, \bar{y}>0 \\ 3 \pi / 2 & \bar{x}=0, \bar{y}<0 \\ \text { 不定 } & \bar{x}=0, \bar{y}=0\end{cases}
$$


corresponding to concentration period $\bar{\alpha}$ is $D_{i}=\bar{\alpha} \frac{T}{2 \pi}$.

Concentration $r$ is a statistical indictor. It describes the central tendency of $\alpha_{i}$ in the circular distribution, $0 \leq r \leq 1$. The closer $r$ is to 0 , the more uniform the distribution of flood occurrence time is. When $r$ is closer to 1 , it means that the flood occurrence time is more concentrated in a certain area. $s$ is the standard deviation of $\alpha_{i}$. The relationship between $r$ and $s$ is as follows:

$$
s=\sqrt{-2 \ln r}
$$

Where $s$ is an index indicating the discrete trend of the flood occurrence time. Then the starting and ending dates $D_{1}$ and $D_{2}$ of the main flood season in the calculation period are respectively:

\subsection{Relative frequency method}

$$
\begin{aligned}
& D_{1}=\frac{\bar{\alpha}-s}{2 \pi} T \\
& D_{2}=\frac{\bar{\alpha}+s}{2 \pi} T
\end{aligned}
$$

The entire flood season is divided into $k$ periods, and the amount of the maximum flood in each period is counted. The equation for the relative frequency of each period is:

$$
R F_{k}=\frac{b_{k}}{n}
$$

Where $R F_{k}$ is the relative frequency of the $k$-th period. $b_{k}$ is the number of annual maximum floods in the $k$-th period, and $n$ is the number of years of flow data.

If the unit is ten days, since the length of each period is different, in order to make each period have the same length, it needs to be adjusted by multiplying the time coefficient. For the last ten-day of the big moon, the ten-day frequency should be multiplied by 10/11, and for the last ten-day frequency of February, it should be multiplied by the coefficient $10 / 8$ (leap year multiplied by $10 / 9$ ). When the algebraic sum $s$ of the initial frequency $R F_{k}$ is not equal to the total of the adjusted $R F_{k}{ }^{\prime} s^{\prime}$, 
generally each $R F_{k}$ ' is multiplied by the coefficient $s / s^{\prime}$, that is, the adjusted relative frequency is:

\section{Analysis on Risk and Benefit}

$$
R F_{k}^{\prime}=R F_{k} \cdot \frac{s}{s^{\prime}}
$$

The flood season staged operation is to adopt different FLWL control schemes. A higher FLWL will bring more benefits, but it will often increase the flood control risk (Apel et al., 2004; Wu et al., 2011; Zhou et al., 2014). On the contrary, a lower FLWL will improve the safety, but it will also result in less utilization benefits. How to raise the FLWL and improve the utilization benefits, and meanwhile ensure the safety of the water conservancy project itself and control flood for the downstream, the most important thing is to conduct a cooperative decision-making analysis on the risk and benefit.

\subsection{Risk Analysis}

During the operation, the events will be happened that are not conducive to the dam safety, threaten the flood control safety of downstream and affect the benefit of reservoir. The occurrence probability and loss of these events is called flood control risk. The flood control risk rate in the extreme state is referred to as the extreme risk rate. With the FLWL $Z_{0}$ as the initial water level, the design flood hydrograph of each frequency is calculated for flood routing. Suppose that $Z_{m}$ is the highest water level of flood routing for the design flood hydrograph of a certain frequency. When $Z_{m}$ is exactly equal to a selected safe level, the frequency is the extreme risk rate $P_{\text {lim. }}$ The selected safe level takes the design flood level $Z_{d}$. The extreme risk rate can be expressed by the following equation:

$$
P_{\lim }=P\left\{Z_{m} \geq Z_{d}\right\}
$$

The procedure for calculating the extreme risk rate is as follows, first select the 
typical flood hydrograph, and then obtain the design flood hydrograph of different frequencies $P_{l}(l=1,2, \ldots, k)$ by zooming in on the typical flood hydrograph. Started to regulate from different FLWL $Z_{i}(i=1,2, \ldots, m, \ldots, n)$, the highest water level $Z_{m l}$ of each frequency is obtained. Finally, plot the different frequencies $P_{l}$ against the highest water level $Z_{m l}$, that is, $n$ different water levels can draw $n$ empirical frequency curves. According to this empirical frequency curve family, the extreme risk rate of a certain FLWL can be found out.

\subsection{Benefit Analysis}

Under the premise of ensuring the flood control safety, the FLWL can be raised as much as possible. It can increase the water head of hydropower generation and water storage. Therefore, the utilization benefit of hydropower generation and water supply are improved accordingly.

\subsubsection{Water Supply Benefit}

Rainfall is mainly concentrated in the flood season. As the FLWL raises, the added water supply capacity mainly comes from the increased storage of abandoned water. In the dry years, there is no water to store after the flood season, the benefits of FLWL adjustment can be clearly reflected. On the contrary, in the wet years, the reservoir can be reserved to the normal water level even if the FLWL is not raised. Raising the FLWL at this time will only bring about the hydropower generation benefit caused by the increased water head, and will not improve the water supply benefit. Therefore, the multi-year average water supply that can be increased by raising the FLWL should be deducted from wet years. In wet years, regardless of the elevation of the FLWL, the water storage task can also be completed. The added water supply volume can be obtained as:

$$
\Delta V_{2}=\Delta V_{1} \times(1-\lambda)
$$


Where $\Delta V_{2}$ is the increased water supply storage. $\Delta V_{1}$ is the increased water storage capacity. According to the curve between water level and capacity, the increased water storage under different FLWL can be obtained. $\lambda$ is the proportion of wet years that can also complete the water storage task with no raising the FLWL.

The increased water supply benefit brought about by the adjustment of the FLWL is:

$$
B_{\Delta}=\Delta V_{2} \times \delta
$$

Where $B_{\Delta}$ is the increased water supply benefit. $\delta$ is the water supply benefit of one cubic meter of water.

\subsubsection{Hydropower generation Benefit}

The improvement of hydropower generation benefit is caused by added water capacity and increased water head. The benefit brought by the increased water capacity is obtained by counting the total hydropower generation water consumption and total hydropower generation of the hydropower station in recent years. The average annual hydropower generation water consumption and annual average hydropower generation are calculated, so as to obtain the average water consumption rate of per unit electric energy. The additional electricity generated by the increased water capacity is expressed as:

$$
E_{1}=\Delta V_{2} / \varphi
$$

Where $E_{1}$ is the additional electricity generated by the increased water volume. $\Delta V_{2}$ is the added water supply capacity, and $\varphi$ is the average water consumption rate of per unit electricity.

The benefit generated by increased water head is expressed by the following equation:

$$
E_{2}=9.81 \cdot \eta \cdot Q_{T} \cdot \Delta H \cdot \Delta T
$$

Where $E_{2}$ is the additional electricity generated by increased water head. $\eta$ is the 
efficiency of the hydropower station, $\eta \in(0,1) . Q_{\mathrm{T}}$ is the maximum hydropower generation flow. $\Delta H$ is the increased height of water head caused by the adjustment of the FLWL, and $\Delta T$ is the calculation time length, here refers to the time length for benefit analysis.

248

\section{Construction of multi-objective cooperative decision-making model}

\subsection{Establishment of multi-objective cooperative decision-making model}

In the comprehensive utilization of reservoirs, flood season operation mainly focuses on flood control operation, and takes into account the water storage to some extent. It is a typical multi-objective decision-making problem. Assuming that the decision-making system has $n$ alternative schemes to choose from, the pros and cons of $n$ schemes are judged according to the characteristic values of $m$ indexes. Then the eigenvalue matrix of $m$ indexes of each scheme is:

$$
X=\left[\begin{array}{cccc}
x_{11} & x_{12} & \mathrm{~L} & x_{1 m} \\
x_{21} & x_{22} & \mathrm{~L} & x_{2 m} \\
\mathrm{M} & \mathrm{M} & \mathrm{O} & \mathrm{M} \\
x_{n 1} & x_{n 2} & \mathrm{~L} & x_{n m}
\end{array}\right]=\left\{x_{i j}\right\}
$$

Where $x_{i j}$ is the eigenvalue of the $j$-th index of the $i$-th scheme, $1 \leq i \leq n$ and $1 \leq j \leq m$.

In the actual decision-making, indexes can be divided into three categories: one is benefit index, that is, the larger the index value, the better. The second is the risk index, that is, the smaller, the better. The third type is the intermediate index. Its membership function generally increases first and then decreases, and it reaches the maximum in the middle part or at a certain point. Due to the different measurement units among indexes, it is impossible to realize union calculation. Various measurement units must be unified quantization, that is, the data of each index must be normalized.

For the benefit index, the equation of the relative membership degree of the 
evaluation index is (Fang et al., 2019):

$$
r_{i j \max }=\frac{x_{i j}-x_{i \min }}{x_{i \max }-x_{i \min }}
$$

For the risk index, the equation is:

$$
r_{i j \min }=\frac{x_{i \max }-x_{i j}}{x_{i \max }-x_{i \min }}
$$

For the intermediate index, the equation is

$$
r_{i j m i d}=\left\{\begin{array}{cc}
1-\frac{x_{i}^{\prime}-x_{i j}}{x_{i}^{*}} & x_{i j}<x_{i}^{\prime} \\
1 & x_{i}^{\prime} \leq x_{i j} \leq x_{i}^{\prime \prime} \\
1-\frac{x_{i j}-x_{i}^{\prime \prime}}{x_{i}^{*}} & x_{i j}>x_{i}^{\prime \prime}
\end{array}\right.
$$

Where $\left[x_{i}^{\prime}, x_{i}^{\prime \prime}\right]$ is the best stable interval of $x_{i j}$.

In equations (14) - (16), $x_{i \max }$ and $x_{i \min }$ are respectively the largest and smallest eigenvalues in the $j$-th $(1 \leq j \leq \mathrm{m})$ index set.

Based on the above, after quantifying and normalizing the indexes in the eigenvalue matrix $X$, the relative superior membership degree matrix $R$ is obtained.

$$
\mathrm{R}=\left[\begin{array}{cccc}
r_{11} & r_{12} & \mathrm{~L} & r_{1 m} \\
r_{21} & r_{22} & \mathrm{~L} & r_{2 m} \\
\mathrm{M} & \mathrm{M} & \mathrm{O} & \mathrm{M} \\
r_{n 1} & r_{n 2} & \mathrm{~L} & r_{n m}
\end{array}\right]=\left\{r_{i j}\right\}
$$

Therefore, in the multi-objective decision-making problem of reservoir operation in flood season, $m$ objectives can be divided into $p$ benefit indexes and $(m-p)$ risk indexes. Then the problem can be described as:

$$
\begin{aligned}
& \max F\left(u_{1}(x), u_{2}(x)\right) \\
& \text { s.t. } g_{k}(x) \geq 0, k=1,2, \mathrm{~L}, T
\end{aligned}
$$

Where $F(x)$ is the objective function, and $T$ is the number of constraint conditions. The multi-attribute utility function $u_{1}(x), u_{2}(x)$ is expressed by the following equations:

$$
u_{1}^{j}(x)=\omega_{1} r_{1 j}+\omega_{2} r_{2 j}+\mathrm{L}+\omega_{p} r_{p j}
$$




$$
u_{2}^{j}(x)=\omega_{p+1} r_{(p+1) j}+\omega_{p+2} r_{(p+2) j}+\mathrm{L}+\omega_{m} r_{m j}
$$

The decision maker obtains the utility winning function by assigning weights to multiple indexes. Based on the above, a multi-objective cooperative decision-making model for reservoir operation in flood season is constructed..

\subsection{Solution of multi-objective cooperative decision-making model}

When establishing a multi-objective cooperative decision-making model, the problem of cooperative decision-making of two index sets is considered. The two index sets are benefit index set $D M_{1}$ and risk index set $D M_{2}$. The cooperation of the two sets means negotiation and agreement can be reached. Let $N=\{1,2\}$ be the sequence number of index sets. For any $i \in \mathrm{N}$, there are $k_{i}$ indexes in the $i$-th decision indexes set.

$$
f_{i}\left(x_{1}, x_{2}\right)=\left(f_{i 1}\left(x_{1}, x_{2}\right), f_{i 2}\left(x_{1}, x_{2}\right), \mathrm{L}, f_{i k i}\left(x_{1}, x_{2}\right)\right) \in G_{i}
$$

Where $G_{i} \subset R^{k i}$ is the reachable target set. $x_{i} \in \Omega_{i} \subset R^{m i}$ is the decision vector. $R^{k i}$ and $R^{k i}$ are $k i$-dimensional and $m i$-dimensional real vector spaces respectively. In the model, the winning function of the index set is represented by the utility function. The multi-attribute utility function of the $i$-th indicator set is:

$$
u_{i}\left(x_{1}, x_{2}\right)=u_{i}\left(f_{i}\left(x_{1}, x_{2}\right)\right)
$$

According to the multi-attribute utility theory, $u_{i}\left(f_{i}\left(x_{1}, x_{2}\right)\right)$ is a strictly monotonic increasing function of each component in $f_{i}$, that is, $\forall i, j=1,2, \ldots, k i$ and $i \neq j$, if $f_{i}\left(x_{1}, x_{2}\right)>$ $f_{j}\left(x_{1}, x_{2}\right), u_{i}\left(f_{i}\left(x_{1}, x_{2}\right)\right)>u_{i}\left(f_{j}\left(x_{1}, x_{2}\right)\right)$.

A pair of utility functions are mapped into a subset $E$ of the two-dimensional Euclidean space $R^{2}$, and $E \subset R^{2}$ represents the joint reachable utility set. The joint reachable utility set of the two index sets is:

$$
E=\left\{\left(u_{1}\left(f_{1}\right), u_{2}\left(f_{2}\right)\right) \in R^{2} \mid f_{i}\left(x_{1}, x_{2}\right) \in G_{i}, x_{i} \in \Omega_{i}, i=1,2\right\}
$$

If $E$ is a closed bounded convex set, $d=\left(d_{1}, d_{2}\right) \in E$ is the current point, and it 
exists $u \in E, u>d$. The current point $\left(d_{1}, d_{2}\right)$ represents the winning function value that can be accepted when the two index sets cannot reach an agreement. The relationship between $E$ and $d$ is called a multi-objective negotiation decision-making problem. If the decision maker assigns $d_{1}>d_{2}$, it means that the index set $D M_{1}$ has greater initiative in the process of negotiation, and the final negotiation result will also be biased towards the index set $D M_{1}$ and vice versa. Suppose that $h(E, d) \in E$ is the solution of $(E, d)$, let $h^{*}(E, d)=u^{*}$, for all $u \in E, u>d$ and $u \neq u^{*}$, there are:

$$
\left(u_{1}^{*}-d_{1}\right)\left(u_{2}^{*}-d_{2}\right)>\left(u_{1}-d_{1}\right)\left(u_{2}-d_{2}\right)
$$

At this time, $h^{*}(E, d)=u^{*}$ becomes the Nash negotiation solution to the multi-objective problem.

If no feasible schemes is exactly the same as the Nash negotiation solution, the fuzzy pattern recognition theory is used to determine the closest, which is the optimal.

\section{Application}

\subsection{Study site}

The reservoir is a large size (1) year regulating reservoir with a watershed area of $1400 \mathrm{~km}^{2}$. The main task of the reservoir is flood control, and the comprehensive utilization of water supply and hydropower generation are taken into account. The total storage capacity is 2.632 billion $\mathrm{m}^{3}$. The flood of 1 in 1000 year's frequency is the designed flood and the flood of 1 in 10000 year's frequency is the checked flood. The designed flood control level is $139.10 \mathrm{~m}$, the corresponding storage capacity is 2.228 billion $\mathrm{m}^{3}$, and the checked flood control level is $143.60 \mathrm{~m}$. The maximum hydropower generation flow of the power station is $200 \mathrm{~m}^{3} / \mathrm{s}$.

The flood season is from May 1st to October 1st, and the designed FLWL is $125.0 \mathrm{~m}$. There is 500 million $\mathrm{m}^{3}$ of flood control capacity above $125.0 \mathrm{~m}$ that is responsible for downstream flood control and peak reduction tasks. When the 
reservoir water level exceeds $125.0 \mathrm{~m}$, the flood discharge tunnel is used for the hydrologic regime of mainstream of the Huai River. When the reservoir water level exceeds $132.60 \mathrm{~m}$, the tunnel is fully opened, with a maximum discharge volume of $618 \mathrm{~m}^{3} / \mathrm{s}$

\subsection{Segmentation of flood season}

The restored daily flow during the flood season of years 1956 - 2017 was used as

343 the basic data for calculation. That is, the sample size $N=62$ years, and the length of

344 the calculation period $T=154$ days.

\subsubsection{Segmentation of flood season by the circular distribution method}

The samples were taken according to different time intervals $t(t=1,3,5,7,10$, 15) to stage the flood season. Firstly, the maximum discharge $q_{L t}(L=1,2, \ldots, n)$ of $t$ days is selected from the $L$-th-year daily discharge in the flood season. Then, various

349 indexes of flood situation are calculated by Eq.(1) - (7). Table 1 and Fig. 1 denote the 350 results of segmentation of different sampling intervals.

Table 1 The result of flood season segmentation by circular distribution method

\begin{tabular}{cccccccc}
$\begin{array}{c}\text { Sampling } \\
\text { intervals } \\
\text { t/天 }\end{array}$ & $\begin{array}{c}\text { Whether to } \\
\text { consider the } \\
\text { flood level }\end{array}$ & $\mathrm{r}$ & $\bar{\alpha}$ & $\overline{\mathrm{D}}$ & $\begin{array}{c}\text { Pre-flood } \\
\text { season }\end{array}$ & $\begin{array}{c}\text { Main flood } \\
\text { season }\end{array}$ & $\begin{array}{c}\text { Post-flood } \\
\text { season }\end{array}$ \\
\hline 1 & $\mathrm{~N}$ & 0.352 & 2.580 & $7 / 2$ & $5 / 1-5 / 17$ & $5 / 18-8 / 7$ & $8 / 8-10 / 1$ \\
& $\mathrm{Y}$ & 0.392 & 3.072 & $7 / 14$ & $5 / 1-6 / 9$ & $6 / 10-8 / 17$ & $8 / 18-10 / 1$ \\
3 & $\mathrm{~N}$ & 0.497 & 2.366 & $6 / 27$ & $5 / 1-5 / 28$ & $5 / 29-7 / 26$ & $7 / 27-10 / 1$ \\
& $\mathrm{Y}$ & 0.418 & 2.838 & $7 / 9$ & $5 / 1-6 / 9$ & $6 / 10-8 / 17$ & $8 / 18-10 / 1$ \\
& $\mathrm{~N}$ & 0.230 & 2.453 & $6 / 29$ & $5 / 1-5 / 17$ & $5 / 18-8 / 10$ & $8 / 11-10 / 1$ \\
& $\mathrm{Y}$ & 0.270 & 3.233 & $7 / 18$ & $5 / 1-6 / 9$ & $6 / 10-8 / 17$ & $8 / 18-10 / 1$ \\
& $\mathrm{~N}$ & 0.437 & 2.038 & $6 / 19$ & $5 / 1-5 / 17$ & $5 / 18-7 / 21$ & $7 / 22-10 / 1$ \\
& $\mathrm{Y}$ & 0.349 & 2.703 & $7 / 5$ & $5 / 1-5 / 30$ & $5 / 31-8 / 10$ & $8 / 11-10 / 1$ \\
& $\mathrm{~N}$ & 0.438 & 1.978 & $6 / 17$ & $5 / 1-5 / 16$ & $5 / 17-7 / 19$ & $7 / 20-10 / 1$ \\
& $\mathrm{Y}$ & 0.359 & 2.553 & $7 / 2$ & $5 / 1-5 / 26$ & $5 / 27-8 / 6$ & $8 / 7-10 / 1$ \\
& $\mathrm{~N}$ & 0.539 & 1.969 & $6 / 17$ & $5 / 1-5 / 20$ & $5 / 21-7 / 15$ & $7 / 16-10 / 1$ \\
& $\mathrm{Y}$ & 0.456 & 2.362 & $6 / 27$ & $5 / 1-5 / 26$ & $5 / 27-7 / 28$ & $7 / 29-10 / 1$ \\
\hline
\end{tabular}




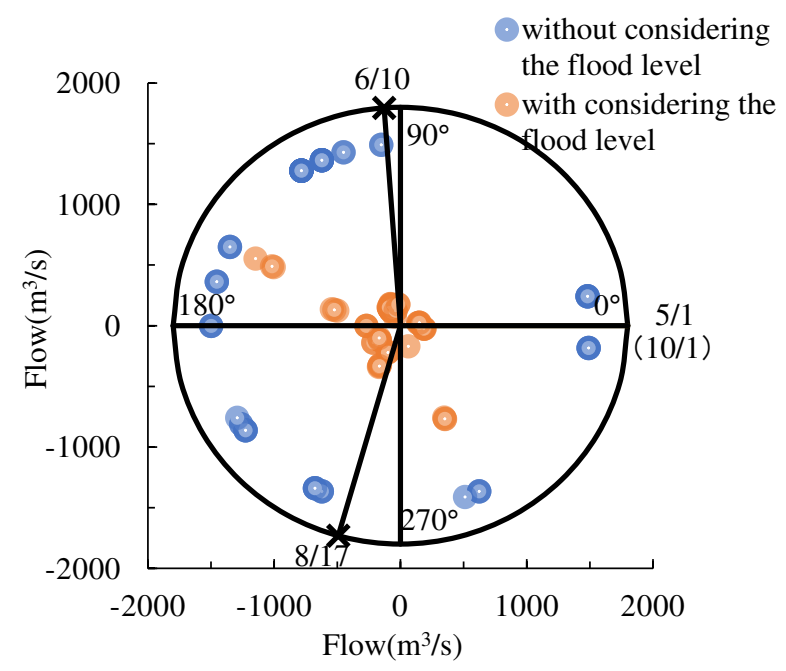

Fig.1 The result of Flood season segmentation by circular distribution method

The segmentation is obtained mainly based on the results of the maximum $t$-day discharge $(t=1,3,5)$ considering the flood magnitude. Table 1 indicated that the calculated main flood season is from June 10 to August 17. Therefore, the main flood season of the reservoir can be obtained as June 10 - August 17.

Fig. 1 shows the occurrence time of the maximum discharge which are expressed in angle. The distribution of data points considering and ignoring the magnitude of the flood which are expressed by the coordinate value of the occurrence time multiplied by the magnitude. Obviously, the points considering the magnitude are concentrated in the period from June 10th to August 17th.

Based on the above, combining the actual situation of the reservoir, the segmentation considering the flood magnitude are selected. The main flood season of the reservoir is gained as June 10 - August 17.

\subsubsection{Segmentation of flood season by the relative frequency method}

Ten days is selected as the unit interval, the whole flood season is divided into 15 periods (October 1 is classified as late September). In each period, the occurrence times of daily maximum discharge over the years 1956-2017 are counted to calculate the relative frequency. The results are shown in the following table. 
Table 2 The result of flood season segmentation by relative frequency method

\begin{tabular}{cccc}
\hline & Period & Times & Relative frequency \\
$R F_{k}$,
\end{tabular}

It can be seen from the Table $\mathbf{2}$ and Fig. 2 that the relatively high frequency is mainly concentrated in the first ten days of June to the middle of August, which is

375 consistent with the flood season segmentation results gotten by the circular distribution method.

\subsection{Analysis of Risk and Benefit}

\subsubsection{Risk Analysis}

Several typical flood hydrographs are selected in the pre-flood season and

380 post-flood season severally, and amplified at the same frequency according to flood

381 peak and flood volume. The flood hydrographs with different design frequencies are

382 deduced. Considering with the flood situation in the reservoir area, the values of 383 frequency $P$ are selected as $0.01 \%, 0.10 \%, 0.20 \%, 1 \%, 2 \%, 3.30 \%, 5 \%, 10 \%$ and $20 \%$ 384 respectively. For the selection of the dynamic domain of FLWL, considering that the 385 original FLWL of the reservoir is $125.0 \mathrm{~m}$, and the normal water level is $130.0 \mathrm{~m}$, the 
FLWLs start at $125.0 \mathrm{~m}$ and increase at a step of $0.5 \mathrm{~m}$ to a maximum of $130.0 \mathrm{~m}$.

Then, taking $Z_{i}$ of each scheme as the starting water level, flood regulation is carried out according to the predetermined dispatching rules. The flood hydrograph that is most unfavorable for the reservoir flood control is selected, and the time interval is 3 h. The relationship between the highest flood regulation water level $Z_{m}\left(Z_{i}\right)$ and the corresponding frequency $\mathrm{P}\left(Z_{i}\right), i=1,2, \ldots, n$ is obtained.

According to the design results of the reservoir, in the pre-flood season, the design flood peak is much smaller than that in the main flood season, but the flood volume is large and the peaks are dense. The flood in 1974 with peak discharge of $3938.84 \mathrm{~m}^{3} / \mathrm{s}$ is selected as the typical. Table 3 presents the results of high water level of flood regulating in the pre-flood season.

Table 3 High water level of flood regulating for different frequency flood under each scheme in the pre-flood season

\begin{tabular}{|c|c|c|c|c|c|c|c|c|c|}
\hline \multirow{2}{*}{ Scheme } & \multirow{2}{*}{$\begin{array}{c}\text { FLWL } \\
/ \mathrm{m}\end{array}$} & \multicolumn{8}{|c|}{ High water level of flood with different frequencies $P / \mathrm{m}$} \\
\hline & & $0.01 \%$ & $0.10 \% \quad 0.20 \%$ & $1.00 \%$ & $2.00 \%$ & $3.30 \%$ & $5.00 \%$ & $10.00 \%$ & $20.00 \%$ \\
\hline 1 & 125.0 & 138.887 & 136.918136 .347 & 135.124 & 134.616 & 134.247 & 133.898 & 133.941 & 133.051 \\
\hline 2 & 125.5 & 139.244 & 137.292136 .730 & 135.522 & 135.026 & 134.657 & 134.310 & 134.355 & 133.470 \\
\hline 3 & 126.0 & 139. & 71137. & 135. & 135.427 & 135.070 & 134.726 & 134 & 133 \\
\hline 4 & 126.5 & 139.971 & $138.047 \quad 137.492$ & 136.315 & 135.830 & 135.472 & 135.140 & 135.179 & 134.312 \\
\hline 5 & 127.0 & 140.326 & 138.420137 .875 & 136.709 & 136.230 & 135.881 & 135.549 & 135 & 134.736 \\
\hline 6 & 127.5 & 140.681 & 138.796138 .255 & 137.101 & 136.627 & 136.282 & 135.959 & 135.999 & 135.155 \\
\hline 7 & 128.0 & 140.912 & 139.178138 .640 & 137.494 & 137.029 & 136.687 & 136.360 & 136.403 & 135.573 \\
\hline 8 & 128.5 & 141.247 & 552139.017 & 137.880 & 137.414 & 137.081 & 136.757 & 136.800 & 135.985 \\
\hline 9 & 129.0 & 141.584 & 139.932139 .398 & 138.270 & 137.810 & 137.477 & 137.160 & 137.201 & 136.393 \\
\hline 10 & 129.5 & 141.928 & 140.305139 .786 & 138.664 & 138.211 & 137.881 & 137.564 & 137.604 & 136.808 \\
\hline 11 & 130.0 & 142.306 & 140.689140 .177 & 139.072 & 138.619 & 138.290 & 137.981 & 138.019 & 137.228 \\
\hline
\end{tabular}

In the post-flood season, the design flood is lighter than that in the main flood season. While compared with the pre-flood season, it has high peak, large volume and many fluctuations, which can reach the standard of once-in-a-thousand-year flood. The flood in 2005 with peak discharge of $7942.69 \mathrm{~m}^{3} / \mathrm{s}$ is chosen as the typical. Table 4 shows the results of high water level of flood regulating in the post-flood season.

Table 4 High water level of flood regulating for different frequency flood under each scheme in 


\begin{tabular}{cccccccccc}
\hline \multirow{3}{*}{ Scheme } & FLWL & \multicolumn{8}{c}{ High water level of flood with different frequencies $P / \mathrm{m}$} \\
\cline { 3 - 10 } & $Z_{i}$ & $0.01 \%$ & $0.10 \%$ & $0.20 \%$ & $1.00 \%$ & $2.00 \%$ & $3.30 \%$ & $5.00 \%$ & $10.00 \%$ \\
\hline 1 & 125.0 & 138.186 & 136.426 & 135.893 & 134.661 & 134.182 & 133.796 & 133.479 & 133.030 \\
2 & 125.5 & 138.550 & 136.808 & 136.279 & 135.070 & 134.593 & 134.209 & 133.898 & 133.447 \\
3 & 126.0 & 138.915 & 137.191 & 136.664 & 135.473 & 135.008 & 134.624 & 134.315 & 133.870 \\
4 & 126.5 & 139.280 & 137.569 & 137.052 & 135.876 & 135.410 & 135.042 & 134.733 & 134.292 \\
5 & 127.0 & 139.649 & 137.953 & 137.437 & 136.274 & 135.819 & 135.450 & 135.151 & 134.715 \\
6 & 127.5 & 140.018 & 138.330 & 137.822 & 136.669 & 136.223 & 135.859 & 135.561 & 135.134 \\
7 & 128.0 & 140.383 & 138.714 & 138.208 & 137.070 & 136.627 & 136.268 & 135.980 & 135.553 \\
8 & 128.5 & 140.737 & 139.091 & 138.585 & 137.457 & 137.022 & 136.666 & 136.376 & 135.965 \\
9 & 129.0 & 141.094 & 139.472 & 138.975 & 137.854 & 137.420 & 137.072 & 136.783 & 136.374 \\
10 & 129.5 & 141.438 & 139.860 & 139.362 & 138.251 & 137.822 & 137.476 & 137.193 & 136.788 \\
11 & 130.0 & 141.788 & 140.249 & 139.762 & 138.658 & 138.233 & 137.891 & 137.608 & 137.209 \\
\hline
\end{tabular}

406

407

408

409

410

411

412

$\frac{\text { Table } 5 \text { Extreme risk rate un }}{\text { Flood limited }}$ displayed in Table 5.

Taking the designed flood control level $(139.10 \mathrm{~m})$ as the selected safe level, the curve of water level and frequency of each scheme is extended or interpolated. Then, the frequency when the flood regulation high water level starting from each FLWL is exactly equal to the selected safe level is obtained, which is named as extreme risk rate. The results of different schemes and corresponding extreme risk rates are

\begin{tabular}{cccc}
\cline { 3 - 4 } Scheme & water level & Pre-flood season & Post-flood season \\
\hline 1 & 125.0 & 0.006 & 0.004 \\
2 & 125.5 & 0.009 & 0.007 \\
3 & 126.0 & 0.015 & 0.011 \\
4 & 126.5 & 0.025 & 0.019 \\
5 & 127.0 & 0.042 & 0.032 \\
6 & 127.5 & 0.071 & 0.056 \\
7 & 128.0 & 0.115 & 0.096 \\
8 & 128.5 & 0.195 & 0.167 \\
9 & 129.0 & 0.339 & 0.293 \\
10 & 129.5 & 0.602 & 0.523 \\
11 & 130.0 & 1.107 & 0.978 \\
\hline
\end{tabular}

As shown above, with the designed flood control level as the selected safe level,

414 Fig. 2 presents the relationship curve between different FLWLs $Z_{i}$ and the corresponding extreme risk rate $P_{\text {lim. }}$ 


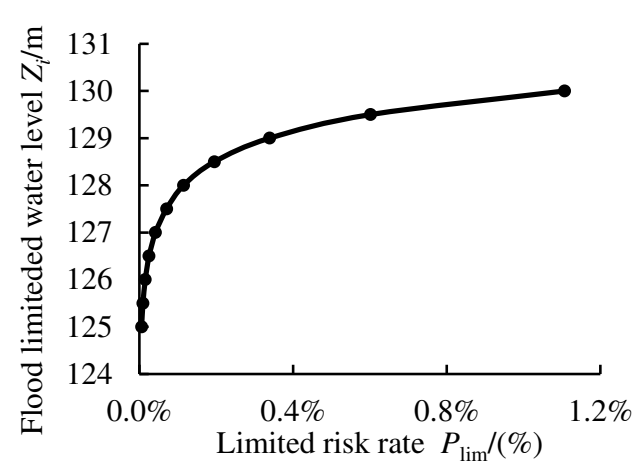

(a) Limited risk rate under different flood limited water levels in the pre-flood season

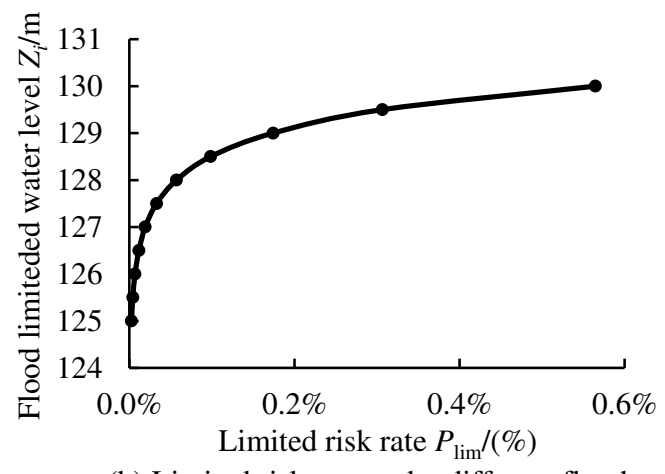

(b) Limited risk rate under different flood limited water levels in the post-flood season

Fig.2 Extreme risk rate under different flood limited water levels

\subsubsection{Benefit Analysis}

The reservoir is a large-scale reservoir. It has the functions of flood control, hydropower generation and water supply. With the adjustment of FLWL, its utilization benefits are mainly reflected in the increase of water supply and hydropower generation. The reservoir supplies water mainly including industrial water, agricultural water, domestic water and ecological water, where seventy percent is used for agricultural water. According to relevant research, the reservoir water supply benefit generated by every cubic water is 35.40 yuan (Zheng, 2020). The hydropower generation operation is subject to the flood control and irrigation operation. After the flood season every year, when the downstream irrigation needs water, the irrigation water is used for hydropower generation. According to the actual operation data of the hydropower station (Yu, 2010), the average annual water consumption for hydropower generation from 1991 to 2008 was 8091.0 million $\mathrm{m}^{3}$, the average annual hydropower generation was 8268 million $\mathrm{kW} \cdot \mathrm{h}$, and the average water consumption rate for unit electric energy was $9.786 \mathrm{~m}^{3}$.

In the pre-flood season, in order to meet the arrival of flood, the reservoir hasn't stored water in advance. The benefit of raising the FLWL only considers the hydropower generation, which positively influenced by the increase of average water head. Eq. (14) is used to calculate the increased hydropower generation benefit. Table 
6 indicates the result in the pre-flood season..

Table 6 Hydropower generation benefit of different schemes in the pre-flood season

\begin{tabular}{ccc}
\hline Scheme & $\begin{array}{c}\text { Water level } \\
(\mathrm{m})\end{array}$ & $\begin{array}{c}\text { Hydropower generation benefit } \\
\left(10^{4} \mathrm{~kW} \cdot \mathrm{h}\right)\end{array}$ \\
\hline 1 & 125.0 & 0 \\
2 & 125.5 & 96.052 \\
3 & 126.0 & 192.104 \\
4 & 126.5 & 288.157 \\
5 & 127.0 & 384.209 \\
6 & 127.5 & 480.261 \\
7 & 128.0 & 576.313 \\
8 & 128.5 & 672.365 \\
9 & 129.0 & 768.418 \\
10 & 129.5 & 864.470 \\
11 & 130.0 & 960.522 \\
\hline
\end{tabular}

In the post-flood season, the reservoir begins to store water to improve the utilization benefit. Therefore, the benefits brought by the adjustment of FLWL include not only the hydropower generation benefit caused by increased water head and volume, but also the water supply benefit. With different starting water levels, the improved water supply benefit can be calculated by Eq. (10). According to the measured hydrological data of the watershed over the years (Hu, 2015), the proportion of wet years that can meet the water supply needs without raising the FLWL is $25 \%$. Deducting the proportion of these years, the actual increased water supply benefit by raising the FLWL can be obtained. Then Eq. (12) is used to calculate the water supply benefit. Table 7 indicates the benefit results in the pre-flood season. 
Table 7 Water supply benefit of different schemes in the post-flood season

\begin{tabular}{ccccc}
\hline $\begin{array}{c}\text { Water level } \\
(\mathrm{m})\end{array}$ & $\begin{array}{c}\text { Storage } \\
\text { capacity } \\
\left(10^{8} \mathrm{~m}^{3}\right)\end{array}$ & $\begin{array}{c}\text { Incremental } \\
\text { storage capacity } \\
\left(10^{8} \mathrm{~m}^{3}\right)\end{array}$ & $\begin{array}{c}\text { Increased water } \\
\text { supply } \\
\left(10^{8} \mathrm{~m}^{3}\right)\end{array}$ & $\begin{array}{c}\text { Increased water } \\
\text { supply benefit } \\
\left(10^{8} \text { yuan }\right)\end{array}$ \\
\hline 125.0 & 12.272 & 0.000 & 0.000 & 0 \\
125.5 & 12.574 & 0.302 & 0.227 & 8.031 \\
126.0 & 12.879 & 0.607 & 0.455 & 16.129 \\
126.5 & 13.187 & 0.915 & 0.686 & 24.307 \\
127.0 & 13.499 & 1.227 & 0.920 & 32.577 \\
127.5 & 13.811 & 1.539 & 1.154 & 40.874 \\
128.0 & 14.126 & 1.854 & 1.391 & 49.237 \\
128.5 & 14.444 & 2.172 & 1.629 & 57.680 \\
129.0 & 14.766 & 2.494 & 1.871 & 66.229 \\
129.5 & 15.094 & 2.822 & 2.117 & 74.937 \\
130.0 & 15.431 & 3.159 & 2.369 & 83.879 \\
\hline
\end{tabular}

459 results in the post-flood season.

460 Table 8 Hydropower generation benefits of different schemes in the post-flood season

\begin{tabular}{|c|c|c|c|}
\hline \multirow{2}{*}{$\begin{array}{l}\text { Water level } \\
\quad(\mathrm{m})\end{array}$} & \multirow{2}{*}{$\begin{array}{l}\text { Increased water } \\
\text { supply benefit } \\
\text { (108 yuan) }\end{array}$} & \multicolumn{2}{|c|}{ Increased hydropower generation benefit } \\
\hline & & $\begin{array}{c}\text { Water volume benefit } \\
\left(10^{4} \mathrm{~kW} \cdot \mathrm{h}\right)\end{array}$ & $\begin{array}{c}\text { Water head benefit } \\
\left(10^{4} \mathrm{~kW} \cdot \mathrm{h}\right)\end{array}$ \\
\hline 125.0 & 0.000 & 0.000 & 0.000 \\
\hline 125.5 & 8.031 & 231.839 & 87.675 \\
\hline 126.0. & 16.129 & 465.593 & 175.350 \\
\hline 126.5 & 24.307 & 701.647 & 263.025 \\
\hline 127.0 & 32.577 & 940.384 & 350.700 \\
\hline 127.5 & 40.874 & 1179.886 & 438.375 \\
\hline 128.0 & 49.237 & 1421.305 & 526.051 \\
\hline 128.5 & 57.680 & 1665.023 & 613.726 \\
\hline 129.0 & 66.229 & 1911.807 & 701.401 \\
\hline 129.5 & 74.937 & 2163.189 & 789.076 \\
\hline 130.0 & 83.879 & 2421.315 & 876.751 \\
\hline
\end{tabular}

\subsection{Nash negotiation solution}

Based on the above calculation results, the benefit index values and risk index

463 values of each scheme in the pre-flood season and post-flood season are listed in 
Table 9 respectively.

Table 9 Benefit and risk index values of different schemes in the pre-flood season and post-flood season

\begin{tabular}{|c|c|c|c|c|c|}
\hline \multirow{3}{*}{$\begin{array}{l}\text { Limited } \\
\text { water level } \\
(\mathrm{m})\end{array}$} & \multicolumn{2}{|c|}{ Pre-flood season } & \multicolumn{3}{|c|}{ Post-flood season } \\
\hline & \multirow{2}{*}{$\begin{array}{c}D M_{1} \\
\text { Hydropower } \\
\text { generation } \\
\text { benefit } \\
\left(10^{4} \mathrm{~kW} \cdot \mathrm{h}\right) \\
\end{array}$} & \multirow{2}{*}{$\begin{array}{c}D M_{2} \\
\text { Limited } \\
\text { risk rate } \\
(\%)\end{array}$} & \multicolumn{2}{|c|}{$D M_{1}$} & \multirow{2}{*}{$\begin{array}{c}D M_{2} \\
\text { Limited } \\
\text { risk rate } \\
(\%)\end{array}$} \\
\hline & & & $\begin{array}{c}\text { Water supply } \\
\text { benefit } \\
\left(10^{8} \text { yuan }\right)\end{array}$ & $\begin{array}{l}\text { Hydropower } \\
\text { generation } \\
\text { benefit } \\
\left(10^{4} \mathrm{~kW} \cdot \mathrm{h}\right) \\
\end{array}$ & \\
\hline 125.0 & 0.000 & 0.006 & 0.000 & 0.000 & 0.004 \\
\hline 125.5 & 96.052 & 0.009 & 8.031 & 319.353 & 0.007 \\
\hline 126.0 & 192.104 & 0.015 & 16.129 & 640.622 & 0.011 \\
\hline 126.5 & 288.157 & 0.025 & 24.307 & 964.190 & 0.019 \\
\hline 127.0. & 384.209 & 0.042 & 32.577 & 1290.440 & 0.032 \\
\hline 127.5 & 480.261 & 0.071 & 40.874 & 1617.457 & 0.056 \\
\hline 128.0 & 576.313 & 0.115 & 49.237 & 1946.390 & 0.096 \\
\hline 128.5 & 672.365 & 0.195 & 57.680 & 2277.623 & 0.167 \\
\hline 129.0 & 768.418 & 0.339 & 66.229 & 2611.921 & 0.293 \\
\hline 129.5 & 864.470 & 0.602 & 74.937 & 2950.817 & 0.523 \\
\hline 130.0 & 960.522 & 1.107 & 83.879 & 3296.458 & 0.978 \\
\hline
\end{tabular}

In order to facilitate comparison between each index, the value of each index necessarily need to be standardized. Eq. (16) is used for benefit index and Eq. (17) is used for risk index. On account of the two benefit indexes of water supply and hydropower generation, considering that the reservoir focus on flood control and water supply, supplemented by hydropower generation, the weight of the two indexes is $(0.6,0.4)$. The utility payoff function values $u_{1}$ and $u_{2}$ are calculated by Eq. (21) (22). Table 10 shows the solution of payoff function values of each scheme.

Table $10 D M_{1}$ and $D M_{2}$ payoff function values of each scheme

\begin{tabular}{ccccccccccccc}
\hline $\begin{array}{c}\text { Payoff function } \\
\text { value }\end{array}$ & 125.0 & 125.5 & 126.0 & 126.5 & 127.0 & 127.5 & 128.0 & 128.5 & 129.0 & 129.5 & 130.0 \\
\hline $\begin{array}{c}\text { Pre-flood } \\
\text { season }\end{array}$ & $u_{1}$ & 0 & 0.1 & 0.2 & 0.3 & 0.4 & 0.5 & 0.6 & 0.7 & 0.8 & 0.9 & 1 \\
Post-flood & $u_{2}$ & 1 & 0.997 & 0.991 & 0.982 & 0.967 & 0.941 & 0.901 & 0.828 & 0.697 & 0.459 & 0 \\
season & $u_{1}$ & 0 & 0.096 & 0.193 & 0.291 & 0.390 & 0.489 & 0.588 & 0.689 & 0.791 & 0.894 & 1 \\
& $u_{2}$ & 1 & 0.997 & 0.992 & 0.984 & 0.970 & 0.946 & 0.903 & 0.829 & 0.695 & 0.459 & 0 \\
\hline
\end{tabular}

Firstly, it is assumed that the winning function values of the two index sets are 
both 0 , that is, the current point $d=(0,0)$. In order to obtain the joint reachable utility set $E$ of the two index sets, the winning function values $\left(u_{1}, u_{2}\right)$ of each flood season are marked, as shown in Fig. 3 below. Then the problem of Nash negotiation is transformed into the following nonlinear programming problems. The corresponding constraints are the line of $\mathrm{AB}$ and $\mathrm{BC}$ in the following Fig. 3.

For pre-flood season:

$$
\begin{array}{cl} 
& \max u_{1} u_{2} \\
\text { s.t. } & 0 \leq u_{1} \leq 1,0 \leq u_{2} \leq 1 \\
& 0.927 u_{1}+u_{2} \leq 1.285 \\
& 1.581 u_{1}+u_{2} \leq 1.722
\end{array}
$$

For post-flood season:

$$
\begin{array}{cc}
\max u_{1} u_{2} \\
\text { s.t. } 0 \leq u_{1} \leq 1,0 \leq u_{2} \leq 1 \\
0.842 u_{1}+u_{2} \leq 1.252 \\
1.493 u_{1}+u_{2} \leq 1.683
\end{array}
$$

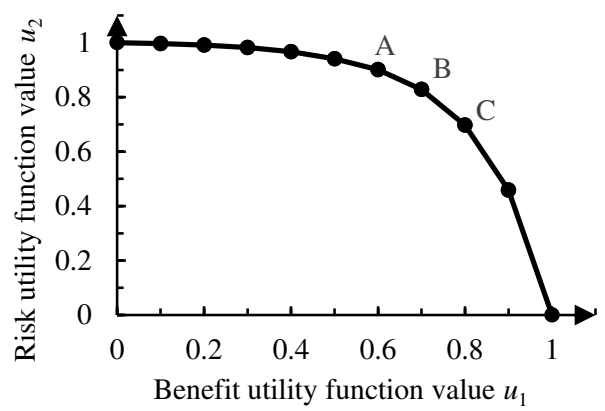

(a) Joint reachable utility set in pre-flood season

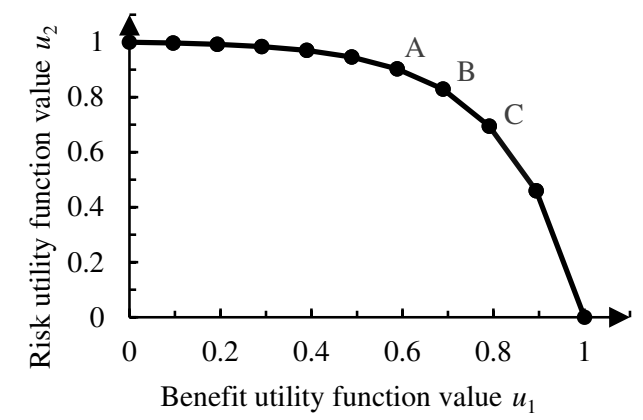

(b) Joint reachable utility set in post-flood

Fig.3 Joint reachable utility set in pre-flood season and post-flood season

Based on the above, the Nash negotiation solution $u_{1}$ in the pre-flood season is 0.918 and $u_{2}$ is 0.669 . In the post-flood season, $u_{1}$ is 0.658 and $u_{2}$ is 0.874 . Since the two negotiation solutions are not equal to $u_{1}$ and $u_{2}$ of each scheme, it is necessary to adopt the fuzzy pattern recognition model and grid schedule theory to calculate the membership degree and decide the optimal scheme. Table 11 presents the membership degree of each scheme and then the optimal water level can be determined. 


\begin{tabular}{cccccccccccc}
\hline $\begin{array}{c}\text { Water level } \\
/ \mathrm{m}\end{array}$ & 125.0 & 125.5 & 126.0 & 126.5 & 127.0 & 127.5 & 128.0 & 128.5 & 129.0 & 129.5 & 130.0 \\
\hline $\begin{array}{c}\text { Pre-flood } \\
\text { season }\end{array}$ & 0.082 & 0.152 & 0.225 & 0.301 & 0.382 & 0.473 & 0.577 & 0.709 & 0.895 & 0.820 & 0.331 \\
$\begin{array}{c}\text { Post-flood } \\
\text { season }\end{array}$ & 0.342 & 0.424 & 0.509 & 0.597 & 0.690 & 0.791 & 0.908 & 0.956 & 0.777 & 0.528 & 0.126 \\
\hline
\end{tabular}

It can be seen from the table that the membership degree is the largest when the water level in the pre-flood season is $129.0 \mathrm{~m}$ and in the post-flood season is $128.5 \mathrm{~m}$. That is, when the current point $d=(0,0)$, the FLWL of the optimal scheme in the pre-flood season is $129.0 \mathrm{~m}$ and in the post-flood season is $128.5 \mathrm{~m}$.

The water level at different sub-seasons of the flood season should be considered according to the specific situation. That is to say, the flood control safety is mainly considered in the pre-flood season, so that the decision preference is risk. In the post-flood season, in order to ensure water supply, decision preference will focus on benefit. The decision-maker changes the preference by changing the current point. Increasing $d_{2}$ means that decision-making biases risk, and the flood control safety is emphatically considered. Similarly, increasing $d_{1}$ means that the decision is biased toward benefit, and the benefits of water supply and hydropower generation are mainly considered. Table 12 presents the specific results. It can be deduced from the and the more utilization benefits can be improved. 


\begin{tabular}{|c|c|c|c|c|c|c|c|c|}
\hline \multirow{3}{*}{$\begin{array}{l}\begin{array}{l}\text { Decision } \\
\text { preference }\end{array} \\
\qquad\left(d_{1}, d_{2}\right)\end{array}$} & \multicolumn{4}{|c|}{ Pre-flood season } & \multicolumn{4}{|c|}{ Post-flood season } \\
\hline & \multirow{2}{*}{$\begin{array}{c}\text { Equally } \\
\text { valued }\end{array}$} & \multicolumn{3}{|c|}{ Risk-biased } & \multirow{2}{*}{$\begin{array}{c}\text { Equally } \\
\text { valued }\end{array}$} & \multicolumn{3}{|c|}{ Benefit-biased } \\
\hline & & $(0,0.1)$ & $(0,0.3)$ & $(0,0.5)$ & & $(0.1,0)$ & $(0.3,0)$ & $(0.5,0)$ \\
\hline $\begin{array}{c}\text { Flood } \\
\text { limited } \\
\text { water level }\end{array}$ & 129.0 & 129.0. & 128.5 & 128.0 & 128.5 & 128.5 & 129.0 & 129.5 \\
\hline
\end{tabular}

\section{Conclusions}

(1) The circular distribution method is used to calculate the concentration degree and concentration period of flood. According to whether the flood magnitude is considered, two situations are analyzed. The start and end date of the main flood season can be acquired. Combined with the results of flood season segmentation and the vector diagram of each flood occurrence time, the results considering the flood magnitude are selected. The results of circular distribution method are verified by relative frequency method, and the verification results are consistent.

(2) The extreme risk rate is selected as the risk index, the water supply benefit and hydropower generation benefit are chosen as the benefit index, normalized, and each index is weighted according to expert experience. Nash negotiation theorem is used to solve the utility payoff function of two index sets. Then, based on the game theory, a multi-objective cooperative decision-making model is established.

(3) Taking a reservoir as an example, based on the cooperative decision-making between risk and benefit, the optimal FLWL control scheme in pre-flood season and post-flood season are obtained. By adjusting the current point to reflect the decision-makers' preference, the decision-makers' expectations for risk and benefit in different sub-seasons can be realized.

\section{Statements and Declarations}

Funding This work was supported by The National Key Research and 
Development Program of China (Grant numbers [2018YFC0407902]).

Competing Interests The authors declare that they have no known competing financial interests or personal relationships that could have appeared to influence the work reported in this paper.

Author Contributions Xiaoying Li: data analysis, original draft preparation and editing; Yan Zhang: investigation, methodology, writing review and editing; Zechun Tong: data analysis, review; Guo-Yue Niu: review, editing. The authors give their full consent for the publication of this manuscript.

Ethics Approval Relevant research content in this paper was in accordance with the ethical standards of the institutional and national research committee.

Consent to Participate All of the authors consent to participate in the relevant research content in this paper

Consent for Publication All the authors have approved the submission and consented for the publication.

Availability of Data and Materials The datasets used or analysed during the current study are available from the corresponding author on reasonable request.

\section{References}

Apel H, Thieken AH, Merz B, Blöschl G (2004) Flood risk assessment and associated uncertainty. Nat Hazards Earth Sys 4(2): 295-308. https://doi.org/10.5194/nhess-4-295-2004

Black A R, Werritty A (1997). Hydrology Seasonality of flooding: a case study of North Britain. J. Hydrol. 195(1-4):1-25. https://doi.org/10.1016/S0022-1694(96)03264-7

Chen JH, Guo SL, Li Y, Liu P, Zhou YL (2013) Joint Operation and Dynamic Control of Flood Limited Water Levels for Cascade Reservoirs. Water Resour Manag 27(3): 749-763. https://doi.org/10.1007/s11269-012-0213-z

Chen J, Zhong PA, Liu WF, Wan XY, Yeh WWG (2020) A multi-objective risk management model for real-time flood control optimal operation of a parallel reservoir system. J Hydrol 590: 
570

Chen L, Guo SL, Yan BW, Liu P, Fang B (2010) A new seasonal design flood method based on bivariate joint distribution of flood magnitude and date of occurrence. Hydrolog Sci J 55(8): 1264-1280. https://doi.org/10.1080/02626667.2010.520564

Chen L, Singh VP, Guo SL, Zhou JZ, Zhang JH, Liu P (2015) An objective method for partitioning the entire flood season into multiple sub-seasons. J Hydrol 528: 621-630. https://doi.org/10.1016/j.jhydrol.2015.07.003

Cunderlik JM, Ouarda TBMJ, Bobée B (2004a) On the objective identification of flood seasons. Water Resour Res 40(1): 1520. https://doi.org/10.1029/2003WR002295

Cunderlik JM, Ouarda TBMJ, Bobee B (2004b) Determination of flood seasonality from hydrological records Hydrolog Sci J 49(3): 511-526. https://doi.org/10.1623/hysj.49.3.511.54351

Fang YH, Zheng XL, Peng H, Wang H, Xin J (2019) A new method of the relative membership degree calculation in variable fuzzy sets for water quality assessment. Ecol Indic 98: 515-522. https://doi.org/10.1016/j.ecolind.2018.11.032

Fang B, Guo SL, Guo FQ, Liu P (2007) Identification of flood seasonality by circular distribution method. J China Hydrol 27(5): 7-11. (in Chinese)

Huang XF, Chen YQ, Lin J, Fang GH, Qu XP, Zhu LX (2017) Research on benefit of reservoir flood resources utilization based on the dynamic control of limited water level. Desalin. Water Treat 79: 214-220. https://doi.org/10.5004/dwt.2017.20857

Hu JL (2015) The study on flood period stage and limited water levels of Meishan Reservoir in Anhui province. Dissertation, Central China Normal University. (in Chinese)

Jiang H, Wang ZZ, Ye A, Liu KL, Wang XH, Wang LJ (2019) Hydrological characteristic-based methodology for dividing flood seasons: an empirical analysis from China. Environ Earth Sci 78(14). https://doi.org/10.1007/s12665-019-8392-z

Jiang HY, Yu ZB, Mo CX (2015) Reservoir Flood Season Segmentation and Optimal Operation of Flood-Limited Water Levels. J Hydrol Eng 20(9) 05014035. https://doi.org/10.1061/(asce)he.1943-5584.0001151

Jiang ZQ, Sun P, Ji CM, Zhou JZ (2015) Credibility theory based dynamic control bound 

optimization for reservoir flood limited water level. J Hydrol 529: 928-939. https://doi.org/10.1016/j.jhydrol.2015.09.012

Ju B, Yu YC, Zhang FH, Lei XH, You FH (2020) Flood season partition and flood limited water level determination for cascade reservoirs downstream jinshajiang river. IOP Conference Series: Earth Environ Sci. 569(1). https://doi.org/10.1088/1755-1315/569/1/012005

Li X, Guo SL, Liu P, Chen GY (2010) Dynamic control of flood limited water level for reservoir operation by considering inflow uncertainty. J Hydrol 391(1-2): 124-132. https://doi.org/10.1016/j.jhydrol.2010.07.011

Liu GJ, Qin H, Shen Q, Tian R, Liu YQ (2019) Multi-objective optimal scheduling model of dynamic control of flood limited water level for cascade reservoirs. Water 11(9): 1836. https://doi.org/10.3390/w11091836

Liu P, Li LP, Guo SL, Xiong LH, Zhang W, Zhang JW, Xu CY (2015) Optimal design of seasonal flood limited water levels and its application for the Three Gorges Reservoir. J Hydrol 527: 1045-1053. https://doi.org/10.1016/j.jhydrol.2015.05.055

Ma C, Xu R, He W, Xia JJ (2020) Determining the limited water level of early flood season by combining multi-objective optimization scheduling and copula joint distribution function: A case study of three gorges reservoir. Sci Total Environ 737. https://doi.org/10.1016/j.scitotenv.2020.139789

Ouyang S, Zhou JZ, Li CL, Liao X, Wang H (2015) Optimal Design for Flood Limited Water Level of Cascade Reservoirs. Water Resour Manag 29(2): 445-457. https://doi.org/10.1007/s11269-014-0879-5

Li Q, Yu HF, Hu LL, Yu WG, Chi YF, Li H (2018) Study on the Stage of Flood Season in Typhoon Affected Area - A case study in Tingxia. IOP Conference Series: Earth Environ Sci 189(5). https://doi.org/10.1088/1755-1315/189/5/052033

Singh VP, Wang SX, Zhang L (2005) Frequency analysis of nonidentically distributed hydrologic flood data. J Hydrol 307(1-4): 175-195. https://doi.org/10.1016/j.jhydrol.2004.10.029

Wu SJ, Yang JC, Tung YK (2011) Risk analysis for flood-control structure under consideration of uncertainties in design flood. Nat Hazards 58(1): 117-140. https://doi.org/10.1007/s11069-010-9653-z 
Xie AL, Liu P, Guo SL, Zhang XQ, Jiang H, Yang G (2018) Optimal Design of Seasonal Flood Limited Water Levels by Jointing Operation of the Reservoir and Floodplains. Water Resour Manag 32(1): 179-193. https://doi.org/10.1007/s11269-017-1802-7

Yu CX (2010) Different period flood analysis and dispatch opinion for the Xianghongdian Reservoir. Jianghuai Water Resour Sci and Technol 2010(1): 19-21. (in Chinese)

Ruan Y, Singh VP (2008) Multiple duration limited water level and dynamic limited water level for flood control, with implications on water supply. J Hydrol 354(1-4): 160-170. https://doi.org/10.1016/j.jhydrol.2008.03.003

Zheng HR (2020) Analysis and evaluation of flood resources utilization in the river basin. Dissertation, Hohai University. (in Chinese)

Zhou HC, Wang FX, Liang GH (2009) Decision-making on reservoir flood control level and its control manner in post-flooding seasons for Biliuhe Reservoir. Adv Water Sci 20(6): 857-862. (in Chinese)

Zhou YL, Guo SL (2014) Risk analysis for flood control operation of seasonal flood-limited water level incorporating inflow forecasting error. Hydrol Sci J 59(5): 1006-1019. https://doi.org/10.1080/02626667.2014.901515

Zhou YL, Guo SL, Liu P, Xu CY (2014) Joint operation and dynamic control of flood limited water levels for mixed cascade reservoir systems. J Hydrol 519(PA): 248-257. https://doi.org/10.1016/j.jhydrol.2014.07.029

Zhou YL, Guo SL, Xu JJ, Zhao XF, Zhai LN (2015) Risk analysis for seasonal flood-limited water level under uncertainties. J Hydro-Environ Res 9(4): 569-581. https://doi.org/10.1016/j.jher.2015.05.001 